\title{
Caracterização Geomorfológica da Carta Jardim do Seridó (SB.24-Z-B-V), Nordeste do Brasil
}

\author{
Geomorphological Characterization of the Jardim do Seridó Chart (SB.24-Z-B-V), \\ Northeast Brazil
}

\begin{abstract}
Paulo Roberto Medeiros Vasconcelos Bacharel em Geografia, Universidade Federal do Rio Grande do Norte, Brasil paulotecminas@gmail.com

George Pereira de Oliveira Mestre em Geografia, Doutorando do Programa de Pós-Graduação em Geografia da UFPE, Brasil

Caio Lima dos Santos Mestre em Geografia, Doutorando do Programa de Pós-Graduação em Geografia da UFPE, Brasil caiolima21@hotmail.com

Marco Túlio Mendonça Diniz Doutor em Geografia, Professor do Programa de Pós-Graduação em Geografia da UFRN, Brasil tuliogeografia@gmail.com

Saulo Roberto de Oliveira Vital Doutor em Geociências, Professor do Programa de Pós-Graduação em Geografia da UFRN, Brasil srovital@gmail.com
\end{abstract}

\section{Resumo}

A diversidade e a dinâmica das feições geomorfológicas desenvolvidas sobre os Maciços Cristalinos do Planalto da Borborema, na área que integra a porção centro sul do Rio Grande do Norte e porção centro norte da Paraíba, especificamente na Folha Jardim do Seridó (SB.24-Z-B-V), são objetos desse estudo. Para compreender o desenvolvimento da paisagem num determinado espaço, se torna essencial a caracterização geomorfológica. Para isso, tomou-se como base metodológica, as propostas de Ross (1992) e IBGE (2009), levando em consideração, também, as legendas adotadas por Ferreira (2010) e Vital (2011), específicas para ambiente semiárido. A partir da metodologia apresentada e da interpretação dos dados topográficos obtidos através de um MDE (Modelo Digital de Elevação), de imagens SRTM (Shuttle Radar Topographic Mission) e de atividades de campo, o mapa geomorfológico da folha foi compartimentado em um domínio morfoestrutural, dois domínios morfoesculturais, duas subunidades morfoesculturais, dois modelados com oito unidades morfológicas variando dos 200 aos 800 metros, o que mostrou ser satisfatório e eficiente, com custos mínimos e tempo reduzido para sua execução. As informações citadas constituem uma importante ferramenta para o planejamento de políticas públicas ambientais e planejamento territorial, assim como para a redução dos riscos e desastres ambientais na área em questão.

Palavras-chave: Mapeamento Geomorfológico; Geoprocessamento; Carta Jardim do Seridó. 


\begin{abstract}
The diversity and dynamics of the geomorphological features developed on the Crystalline Massifs of the Borborema Plateau, in the area that integrates the south-central portion of Rio Grande do Norte and the north-central portion of Paraíba, specifically in the sheet Jardim do Serido (SB.24-ZBV), are objects of this study. To understand the development of the landscape in a given space, it becomes essential the geomorphological characterisation. For this, the proposals of Ross (1992) and IBGE (2009) were taken as a methodological basis, taking into account also the legends adopted by Ferreira (2010) and Vital (2011), specific for semiarid environment. Based on the presented methodology and the interpretation of topographic data obtained through an MDE (Digital Elevation Model), SRTM images (Shuttle Radar Topographic Mission) and field activities, the geomorphological map of the sheet was compartmentalized in a morphostructural domain, two morphoscultural domains, two morphoscultural subunits, two modeled with eight morphological units ranging from 200 to 800 meters, which proved to be satisfactory and efficient, with minimum costs and reduced time for its execution. The information cited is an essential tool for planning public environmental policies and territorial planning, as well as for the reduction of environmental risks and disasters in the area in question.
\end{abstract}

Keywords: Geomorphological Mapping; Geoprocessing; Jardim do Seridó Chart.

\title{
1. INTRODUÇÃO
}

A compreensão da dinâmica natural enquanto formadora dos processos de evolução da paisagem é uma ação bastante complexa, o que constitui uma preocupação básica das Geociências e, em especial, da Geomorfologia. Diante disso, a Geografia como uma ciência que inclui a geomorfologia como sub-ramo, pode contribuir substancialmente na análise do relevo, não apenas sob uma perspectiva natural, mas também socioambiental. Em seu estudo, Ross (1992) estabelece que para o satisfatório esclarecimento da morfogênese, é preciso diferenciar as formas herdadas das formas funcionais atuais.

Christofoletti (1980) buscou entender o relevo através da ligação dos processos com as formas, considerando ambos como um sistema aberto que tanto recebe como atua sobre influências de outros sistemas de um conjunto maior, pois os mesmos não atuam em particular e sim em conjunto.

O estudo das formas do relevo, assim como sua origem, estruturação dos materiais e as ações que nele estão atuando é produto da ciência geomorfológica (FLORENZANO, 2008). De acordo com a referida autora, o relevo é a relação das trocas de energia e matéria que estão evoluindo segundo influências conjuntas da litosfera, atmosfera, hidrosfera e biosfera.

Para Corrêa (2010), o relevo é o resultado da interação entre as forças motoras endógenas e exógenas, tendo como resultado a esculturação das formas. Ou seja, é o produto da atuação dos processos internos e externos da Terra, que colaboram para que essas atividades estejam em constantes modificações.

De acordo com Ross (1992), há diversas ordens de extensão das formas de relevo, e, para identificá-las, são associadas suas idades, os tipos de processos que atuaram e os que estão atuando, 
pois quanto maior a dimensão do relevo, mais antiga é a idade de sua formação, e quanto menor a dimensão, mais recente é sua gênese. Diante dessa perspectiva, esse mesmo autor explica a partir de análises voltadas para os processos geomorfológicos e para a identificação do nível de degradação da estrutura superficial da paisagem, que é necessário obedecer a uma ordem taxonômica para fins de padronização dos mapeamentos sistemáticos direcionados para o planejamento ambiental e territorial.

O sistema taxonômico apresentado pelo mesmo propõe a compartimentação do relevo em seis unidades hierárquicas, onde as maiores e menores estruturas do relevo estão diretamente associadas aos tipos de litologia e também as ações climáticas do passado e da atualidade. As unidades morfoestruturais correspondem ao primeiro táxon, o qual é constituído pelas megaestruturas do relevo, relacionadas aos agentes endógenos (erupções vulcânicas e tectonismo). Como segundo táxon têm-se as unidades morfoesculturais, resultantes dos agentes exógenos (chuvas, ventos, etc.), que são geradas pela ação climática atual e pretérita. O terceiro táxon se refere às Unidades dos Padrões de Formas Semelhantes do Relevo ou Padrões de Tipos do Relevo que constitui um conjunto de distintas formas menores definidas por seu padrão de rugosidade. O quarto táxon, por sua vez, diz respeito às formas de relevo individualizadas dentro de cada Unidade de Padrão de Formas Semelhantes, onde se encontram os modelados de agradação e denudação. O quinto táxon, por sua vez, compreende as formas de vertentes, e o sexto táxon é associado com a atuação antrópica sobre o meio ambiente, ou seja, as formas produzidas por processos erosivos e agradacionais atuais relacionadas às ravinas, movimentos de massa, dentre outros (ROSS, 1992).

Com relação a proposta existente em IBGE (2009), têm-se como primeiro táxon os domínios morfoestruturais, como segundo táxon as regiões geomorfológicas, o terceiro táxon as unidades geomorfológicas e o quarto táxon os modelados (acumulação, aplanamento, dissolução e dissecação). O quinto táxon, por sua vez, compreende as formas de relevo simbolizadas. Para individualizar um conjunto de formas é necessário utilizar os conhecimentos prévios fornecidos pela Geologia e Climatologia, a fim de compreender a evolução das formas do relevo e das paisagens existentes. Esses parâmetros são desenvolvidos a partir da natureza estrutural, litológica, pedológica, climática e morfodinâmica de uma determinada área.

Conforme Casseti (2005), o mapeamento geomorfológico serve para representar as formas e os processos da superfície da terra, sendo capaz de compartimentar o relevo em unidades de acordo com suas características e relações litológicas e estruturais semelhantes, derivadas das ações climáticas que atuaram no passado e atuam no presente, e que resultaram no modelado atual da paisagem, de modo que possa tratar as unidades individualmente.

Hétu (2003) afirma que a nomenclatura utilizada nos estudos geomorfológicos é de caráter complicado, totalizando vários conceitos difíceis de dominar. Ele ressalta que a confecção de mapas 
geomorfológicos padronizados visa contribuir para uma gestão ambiental adequada, que oferece um suporte de caráter mais sólido, prevenindo a população dos riscos naturais.

No Brasil, há os problemas de gestão dos espaços, de modo que colaboram para que o planejamento não consiga alcançar um modelo de representação que satisfaça os diferentes interesses geomorfológicos. Nesse sentido, os estudos de planejamento territorial e ambiental, dentre outros, necessitam substancialmente, de produtos com qualidade, advindos da cartografia geomorfológica.

O estudo da geomorfologia possui grande interesse na compreensão da dinâmica da paisagem, contribuindo para interpretações acerca das condições ambientais (COELHO, 2008). Sob essa perspectiva, para esse autor os mapeamentos geomorfológicos possuem um caráter crucial para o planejamento ambiental de uma área.

Atualmente, os mapeamentos geomorfológicos são elaborados com o uso e interpretação de imagens de satélite, de radares, e de Aeronaves Remotamente Pilotadas (RPA), onde são necessários a aquisição, produção, armazenamento e manipulação de dados espaciais.

Levando em consideração o exposto e a escassez de produtos cartográficos de detalhe e semi detalhe da geomorfologia do estado do Rio Grande do Norte, o presente estudo pretende mapear e descrever/caracterizar os compartimentos geomorfológicos que compõem o relevo regional, em nível de detalhe. Além disso, a área apresenta um diversificado mosaico de feições do relevo e informações geológicas detalhadas para a região, o que torna a delimitação das unidades de relevo mais detalhadas. Estas que são desenvolvidas sobre os maciços cristalinos do Planalto da Borborema, na área que integra a porção centro sul do Rio Grande do Norte e porção centro norte da Paraíba, Nordeste do Brasil, especificamente na área da folha Topográfica Jardim do Seridó (SB.24-Z-B-V) na escala de $1: 100.000$.

Oferecer um produto cartográfico eficaz, capaz de nortear ações de planejamento territorial, é um dos propósitos desse estudo. Nesse contexto, o mapeamento geomorfológico serve como importante instrumento para elaborar um diagnóstico acerca das potencialidades e fragilidades dos ambientes naturais (Ross, 1994), sendo capaz de subsidiar a apropriação do espaço de forma racional e sustentável, com auxílio para a análise da degradação da estrutura superficial da paisagem até o quarto táxon.

\section{MATERIAIS E MÉTODOS}

\section{1 Área de estudo}

A área de estudo abrange a carta topográfica Jardim do Seridó (SB.24-Z-B-V), com escala de 1:100.000, delimitada pelas coordenadas planas $714000 \mathrm{mE}$ e $784000 \mathrm{mN}$ de longitude; e $9225000 \mathrm{mE}$ e $9285000 \mathrm{mN}$ de latitude, o que corresponde à porção centro sul do estado do Rio Grande do Norte 
e Centro Norte da Paraíba, abrangendo os seguintes municípios: Acari, Caicó, Carnaúba dos Dantas, Equador, Jardim do Seridó, Ouro Branco, Parelhas, Santana do Seridó e São José do Seridó, e, também, os municípios paraibanos Frei Martinho, Juazeirinho, Junco do Seridó, Nova Palmeira, Pedra Lavrada, Santa Luzia, São José do Sabugi, São Mamede, Seridó, Tenório e Várzea (MORAIS, 2005; SEPLAN, 2000) (Figura 1).

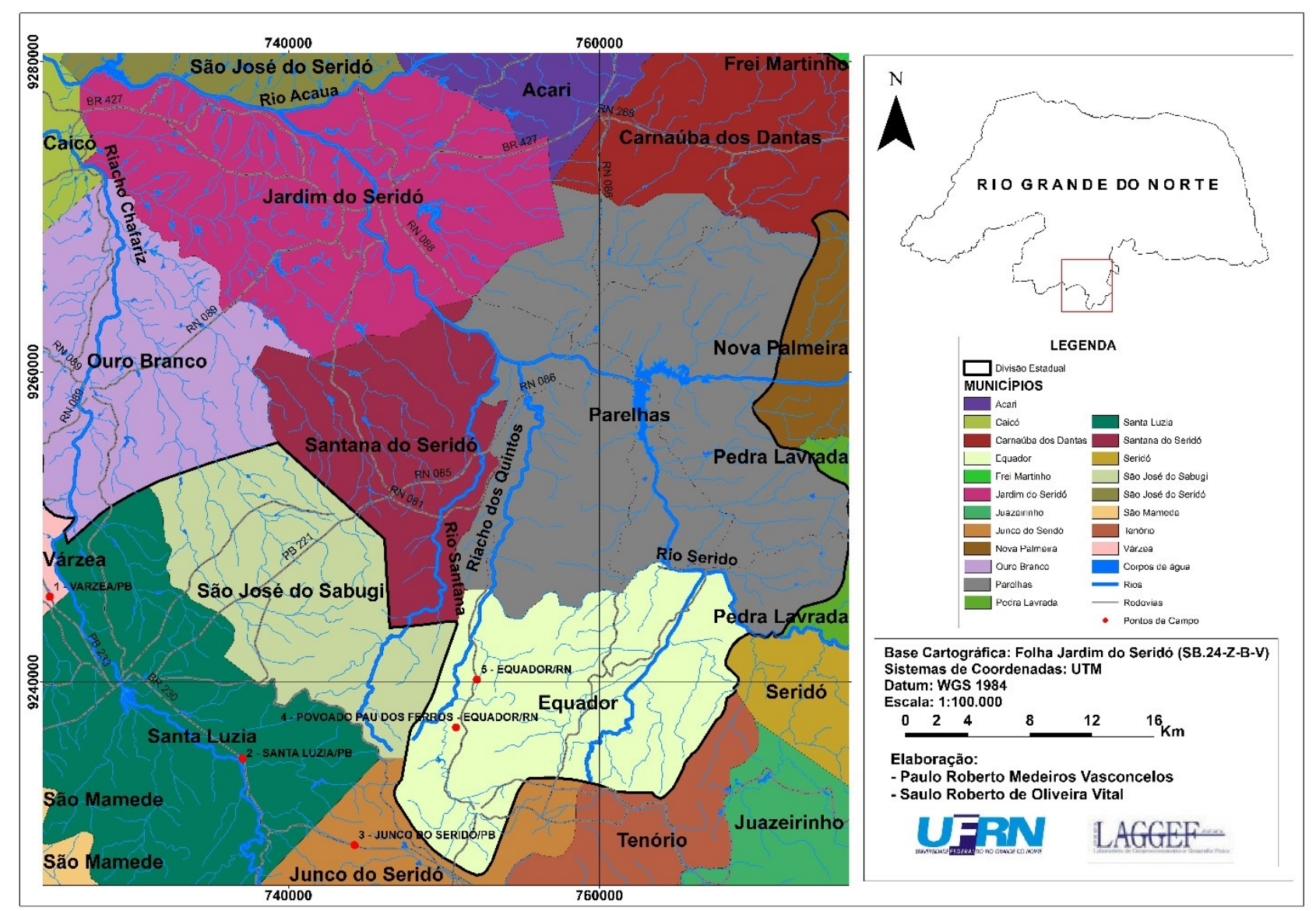

Figura 1 - Localização e municípios que abrangem a Carta Jardim do Seridó (SB-24-Z-B-V).

Fonte: Os autores (2018).

Geologicamente, de acordo com Angelim, Medeiros, Nesi (2006) a área está situada na Província Borborema, no Domínio Rio Piranhas-Seridó, limitada tectonicamente, a oeste, pelo Domínio Jaguaribeano, através da zona de cisalhamento Portalegre, e, a leste, pelo Domínio São José do Campestre através da zona de cisalhamento Picuí - João Câmara. Ainda segundo os referidos autores, esse domínio é embasado por rochas metaplutônicas e metavulcanossedimentares do Complexo Caicó (rochas ortognáissicas e sequências metavulcanossedimentares, quartzo-feldspatobiotita gnaisse migmatizado), com idades aproximadas de 2.300 a 2.050 milhões de anos.

Na cobertura desse Domínio, na porção central e na maior parte da área há uma dominação das rochas neoproterozóicas supracristais do Grupo Seridó ou Faixa Seridó, constituída pelo Grupo Seridó, composta pelas formações Serra dos Quintos, Jucurutu, Equador e Seridó, que também são 
de origem metamórficas (gnaisses, mármores, quartzitos, xistos, etc.) (ANGELIM, MEDEIROS, NESI, 2006). A referida área perfaz uma faixa de dobramentos associados à Orogênese Brasiliana/Panafricana ocorrida a cerca de 640 a 580 Milhões de anos (BRITO NEVES, 1999).

Quanto à caracterização geomorfológica da região, Maia, Amaral e Gurgel (2013); Maia e Bezerra (2014); e Azevedo (2014), descrevem que os domínios geomorfológicos da Depressão Sertaneja (domínio de maior extensão da área de estudo, que integra o relevo plano e suave de uma superfície de erosão sedimentar) e do Planalto da Borborema (área que se estende pelos estados de Alagoas, Ceará, Paraíba e Pernambuco, compreendendo o relevo ondulado com topos retilíneos ou convexos em litologias cristalinas) são claramente envolvidos pela disposição morfoestrutural. A área mencionada possui cotas altimétricas variadas, desde planícies até relevos montanhosos com vales em forma de $\mathrm{V}$ e U, que se encontram sobre as rochas cristalinas de origem pré-cambriana.

Essa área localiza-se na porção setentrional do Nordeste, pontuada por compartimentos geomorfológicos cuja evolução atual é condicionada pelas heranças estruturais do Ciclo Brasiliano e da reativação cretácea (BRITO NEVES, 1999), composta por diversos lineamentos estruturais e zonas de cisalhamentos que orientam a drenagem e a dissecação das bacias mesozoicas afetadas por soerguimento (MAIA e BEZERRA, 2014).

Acerca dos tipos de solos, Azevedo (2014) afirma que, na região, há solos fortemente pedregosos do tipo Neossolo Litólico e Luvissolo Crômico. Essas coberturas pedológicas possuem pouco desenvolvimento, são bastante rasos, onde a rocha se encontra a menos de $50 \mathrm{~cm}$ de profundidade, além de possuírem baixa retenção de água, fertilidade mediana e alta fragilidade erosiva. Além desses, também podem ser encontrados Neossolos Quartzarênicos e Latossolos em alguns pontos específicos (EMBRAPA, 2009).

O clima da região é classificado como Semiárido do tipo Tropical quente e seco, que se caracteriza por um curto período na distribuição espacial das chuvas, onde a intensidade da precipitação é alta em um curto espaço temporal, que se estende nos meses de fevereiro a abril, ocasionando a erosão e deposição de materiais durante os eventos climáticos úmidos. A dinâmica climática dessa região é influenciada por diversos sistemas atmosféricos, onde se destaca a Zona de Convergência Intertropical (ZCIT) e os Vórtices Ciclônicos de Altos Níveis (VCAN). No restante do ano, se prolonga o período de seca. Além disso, a área sofre com altas taxas de evapotranspiração, com insolação predominante em quase todo o ano. As temperaturas se apresentam entre mínima de $27^{\circ} \mathrm{C}$ e máxima de $38^{\circ} \mathrm{C}$ anuais, com umidade relativa do ar muito baixa (MAIA e BEZERRA, 2014; PTDRS, 2010).

Em relação à hidrografia, a área de estudo encontra-se inserida na bacia hidrográfica do rio Piranhas-Açu, que é a maior bacia hidrográfica do estado do Rio Grande do Norte, cujo principal rio é o Piranhas-Açu, o qual tem sua nascente no estado da Paraíba e sua foz no Oceano Atlântico, 
próxima ao município de Macau na costa do Rio Grande do Norte. Outras drenagens importantes que podem ser destacadas são o rio Acauã, rio Malhada Grande, rio das Vazantes, riacho Chafariz e rio Seridó, sendo esse último o principal rio da bacia que drena a área de estudo, assim como alguns tributários, açudes e barragens que fazem parte dessa bacia hidrográfica (MMA, 2005; PTDRS, 2010).

A vegetação predominante é composta pelo domínio da Caatinga hiperxerófila, denominada pelo IBGE (2012) como Savana-Estépica Gramíneo-Lenhosa, com um estrato herbáceo bem preciso. A Caatinga, por ser um domínio completamente heterogêneo, devido às alterações que acontecem, muitas vezes, em razão do clima, apresenta aparência de cor cinza, de pequeno porte, seco, ralo e muito resistente aos longos períodos de seca, mas que muda completamente aos primeiros sinais de chuva (AZEVEDO, 2014; SEPLAN, 2000).

O processo de ocupação do Seridó Potiguar se deu por volta do século XVII, inicialmente para a criação de gado e a agricultura de subsistência. Por volta do século XIX surgiu o algodão, que também influenciou na transformação desse território. Posteriormente no século XX despontou a mineração e a panificação, onde a extração de lenha e a produção de carvão para serem utilizados nos fornos dessas atividades influenciaram na alteração dos recursos naturais, impactando tanto a vegetação como o solo (MMA, 2005; AZEVEDO, 2014).

\subsection{Procedimentos metodológicos}

Nessa pesquisa foi adotada a proposta metodológica taxonômica apresentada por Ross (1992) e IBGE (2009), onde foram consideradas as quatro primeiras classes taxonômicas. No tocante ao quarto táxon, foi adotada exclusivamente a segunda proposta supracitada, uma vez que ela define quatro tipos de modelados: acumulação, denudação, aplanamento e dissolução, o que a torna mais ampla. No tocante às legendas específicas para o semiárido, foram adotadas as propostas de Ferreira (2010) e Vital (2011).

Como área geográfica foram utilizados os limites da folha topográfica Jardim do Seridó (SB.24-Z-B-V), na escala de 1:100.000, obtida por meio do Banco de Dados Geográficos do Exército (BDGEx). Além disso, também foram utilizados os dados altimétricos da imagem de radar da missão SRTM (Shuttle Radar Topography Mission) disponibilizados no Brasil pela EMBRAPA (Empresa Brasileira de Pesquisa Agropecuária) com resolução de 90m, Datum WGS 1984.

Com a aquisição do banco de dados, a imagem SRTM foi inserida junto com a folha Jardim do Seridó e manipulada no programa ArcMap versão acadêmica 10.3. Posteriormente, foi executado o tratamento e modelagem dos dados cartográficos através do georreferenciamento, digitalização e 
vetorização das informações contidas na folha (drenagens, estruturas, corpos de água, municípios, estradas e rodovias).

Também foram realizadas atividades de campo, onde foram registrados os pontos de localização com Sistema de Posicionamento Global junto aos registros fotográficos, para coletar informações referentes às superfícies do relevo, para posterior validação do mapa geomorfológico. As unidades geomorfológicas foram delimitadas a partir de interpretação visual, sobretudo, com base na altimetria. Porém, também foram levados em consideração a fisionomia do relevo, com base em imagens de satélite. Outro importante meio de identificação das unidades de relevo foi o trabalho de campo (Figura 2).

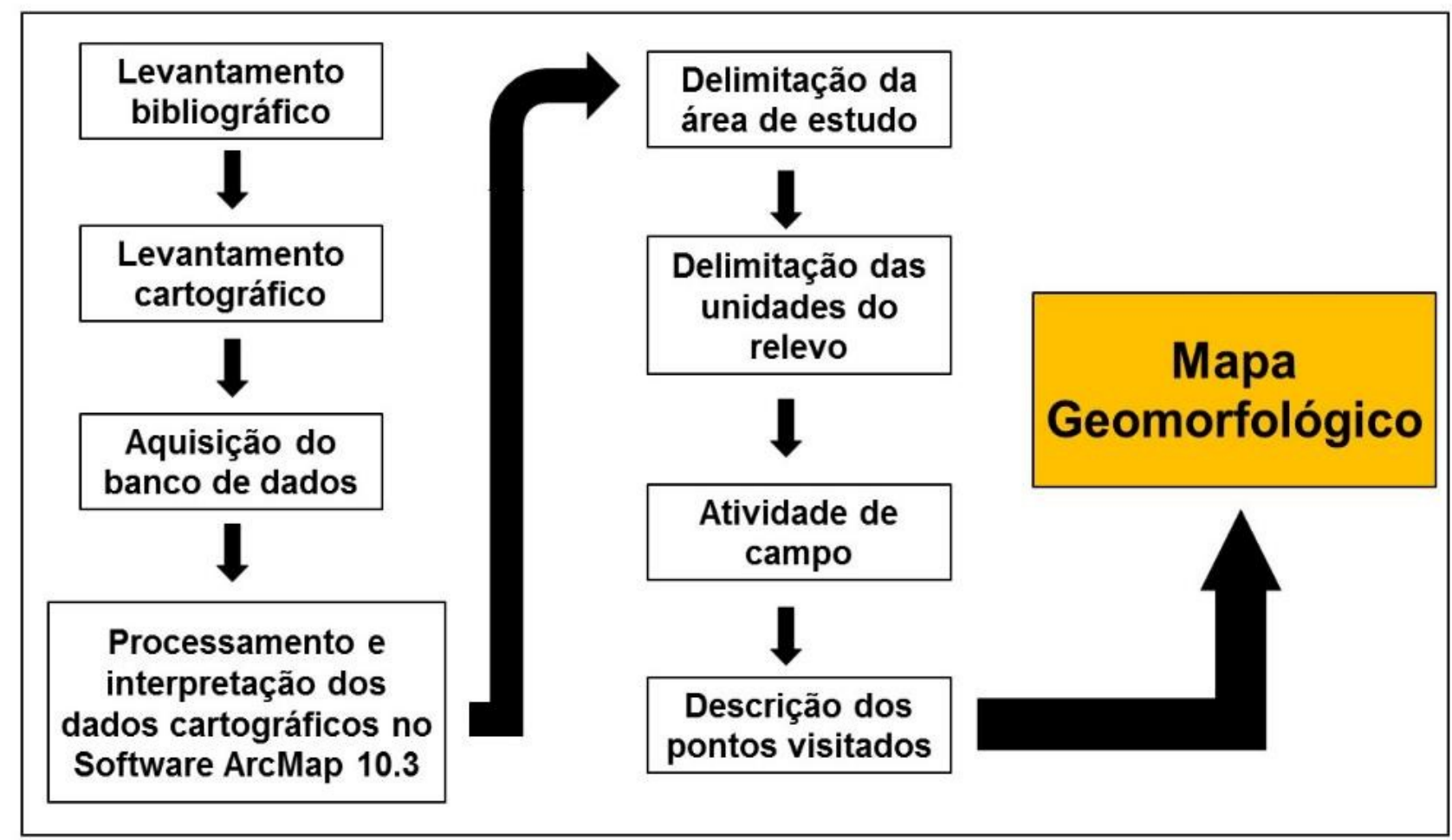

Figura 2 - Fluxograma representando as etapas metodológicas utilizadas nesse estudo. Fonte: Os autores (2018).

\section{RESULTADOS E DISCUSSÃO}

A partir da análise do mapa geomorfológico, foi possível observar que a rede de drenagem é formada por diversas bacias hidrográficas orientadas na direção SE-NW, onde, geralmente, ocorrem vales encaixados conforme as estruturas geológicas (Figura 3).

Além disso, percebeu-se que os cursos d'água naturais contidos na folha topográfica estudada, possuem padrões de drenagens dendríticas, retilíneas e paralelas, com regime de vazões intermitentes ou temporárias. No setor sudoeste também foram observadas drenagens retangulares, o que demonstra forte controle estrutural. 
Com a perspectiva desses pontos visitados e a construção do mapeamento geomorfológico, foi possível reforçar os resultados discutidos, para, assim, propor uma compartimentação geomorfológica para a região abordada.

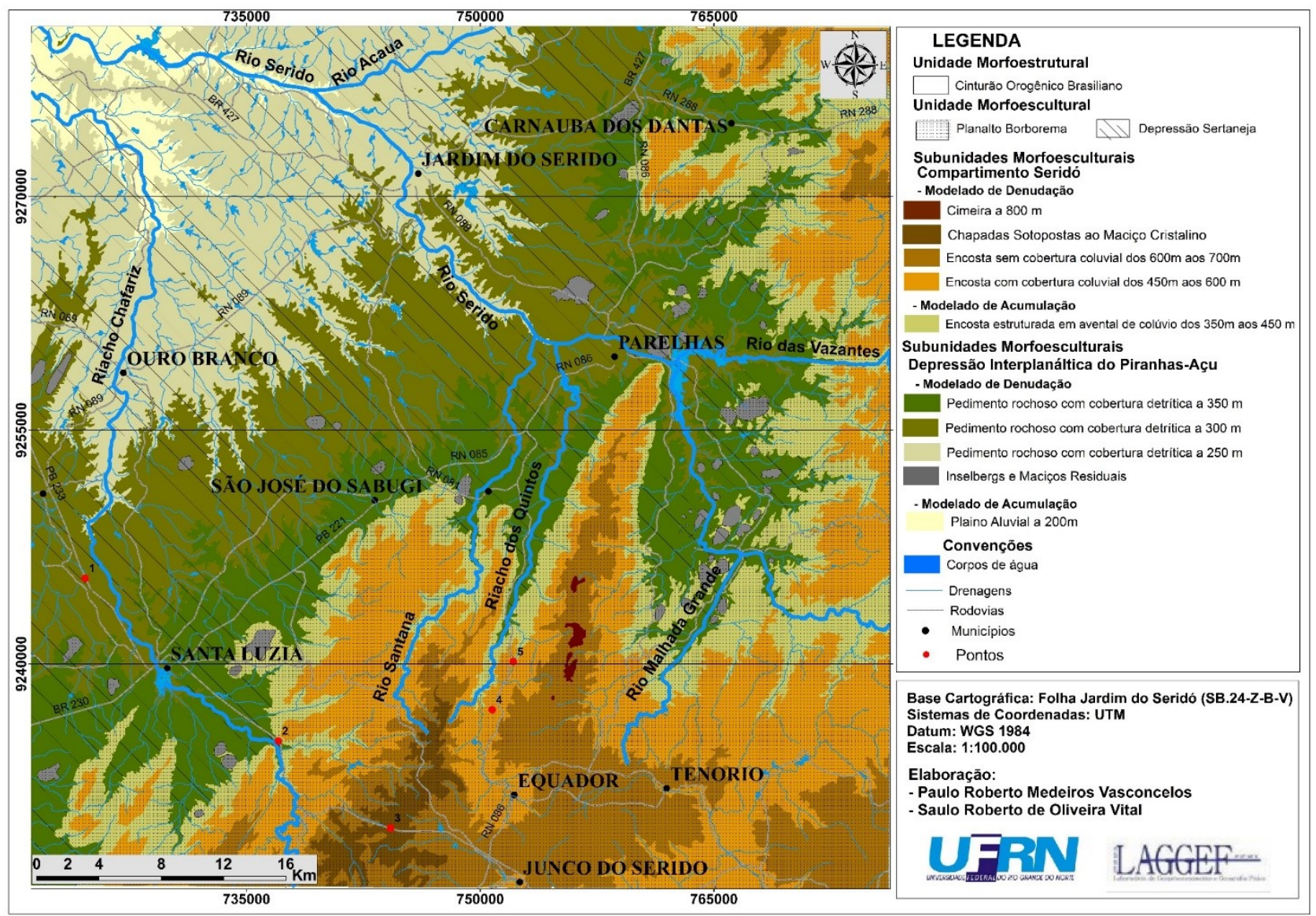

Figura 3 - Geomorfologia da Carta Jardim do Seridó.

Fonte: Os autores (2019).

No primeiro ponto, situado próximo às margens da rodovia PB-233, trecho que liga o município de Várzea/PB a Santa Luzia/PB, na Subunidade Morfoescultural Depressão Interplanáltica do Piranhas-Açu e Modelado de Denudação Pedimentos Rochosos com Cobertura Detrítica (250$350 \mathrm{~m}$ ), a superfície se encontra em fase de aplainamento com inclinação suave, apresentando cotas altimétricas de, em média, 300 metros. Foi possível observar nesse setor, um intenso processo de intemperismo físico a partir da exposição de feições ruiniformes com intenso fraturamento e avançado estágio de esfoliação esferoidal. Nesse compartimento, os processos erosivos são pouco intensos, em virtude da topografia semiplana. A partir desse ponto, também foi possível observar as escarpas ocidentais do Planalto da Borborema, no contato com a superfície da Depressão Sertaneja (Figura 4a).

Nesse trecho da área de estudo, as elevações possuem baixa altimetria, constituindo um terreno pouco acidentado, capeados por sedimentos de cascalho e areia que são transportados e 
depositados em função da alta energia das drenagens, próprias do semiárido. Esse quadro é atestado ao analisar a imagem SRTM, a partir da qual é possível notar o intenso trabalho das drenagens, exibindo forte dissecação, em diferentes direções de fluxo. Conforme Maia e Bezerra (2014), a morfogênese dessa região possui ampla participação da erosão diferencial e da movimentação neotectônica, controlando a suavização do relevo e a orientação da drenagem (Figura 4b).

A área se encontra parcialmente vegetada, onde há algumas zonas com espécies de caatinga arbórea arbustiva esparsa e, em outras, há caatinga arbórea arbustiva fechada, com forte presença de capim panasco (Agrostis stolonifera) e jurema-preta (Mimosa tenuiflora), com aparente uso de ações antrópicas de desmatamento, mas sem cultivo agrícola (Figura 4d).

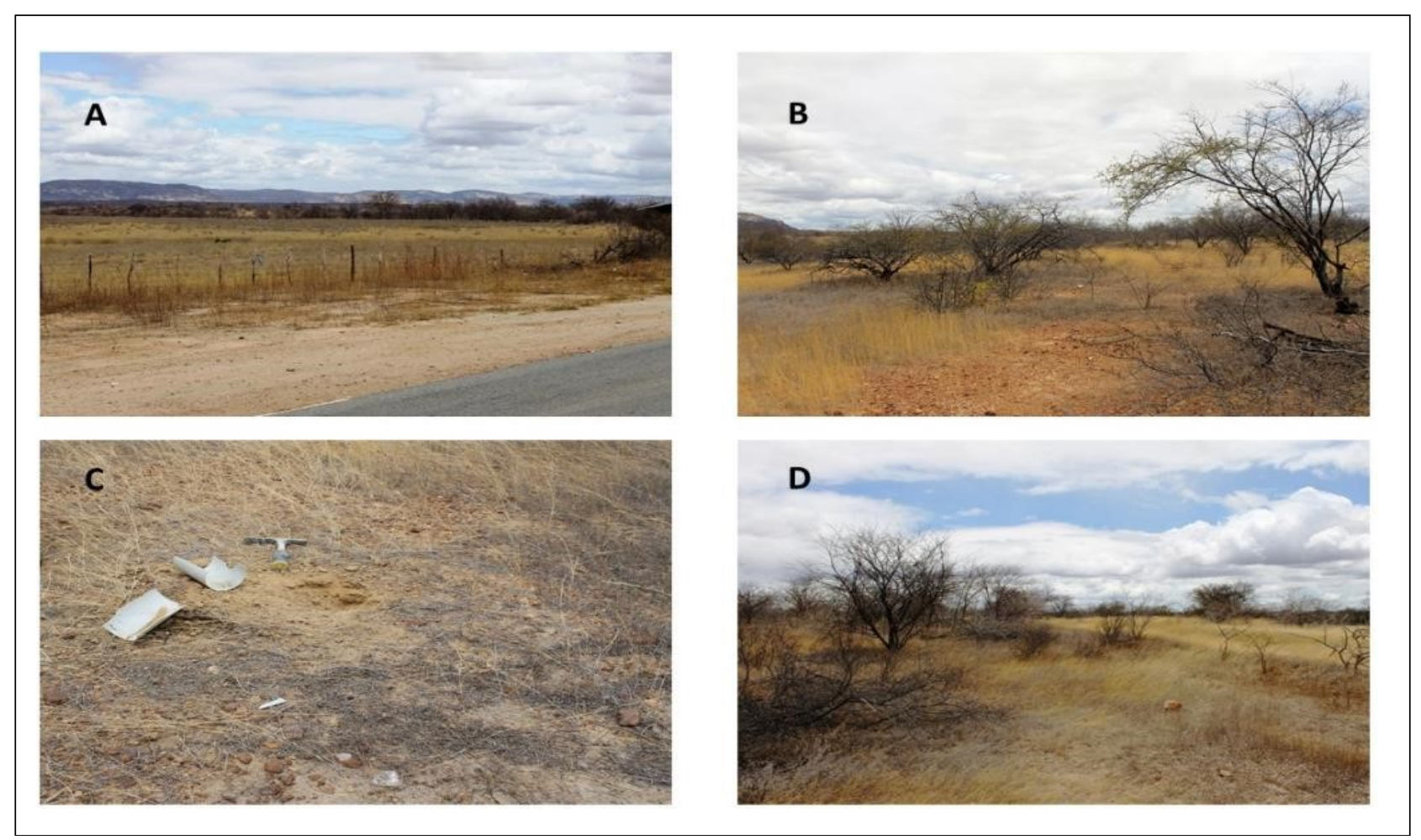

Figura 4 - A e B - Superfície de aplanamento com aspecto acidentado no contato com a escarpa ocidental da Borborema ao fundo. C e D - Solo bastante raso e pedregoso pouco vegetada, com aparente uso de ações antrópicas. Fonte: Os autores (2018).

Outra localidade bastante representativa, se encontra no município de Santa Luzia/PB, onde se observa o limite da Subunidade Morfoescultural Depressão Interplanáltica do Piranhas-Açu com as escarpas ocidentais da Subunidade Morfoescultural Compartimento Seridó, no trecho da rodovia BR-230 que liga ao município de Junco do Seridó/PB, numa altitude de $350 \mathrm{~m}$. No tocante ao modelado, esse ponto corresponde ao contato entre o Pedimento Rochoso com Cobertura Detrítica (250-350 m) e a Encosta Estruturada em Avental de Colúvio (350-450 m).

Em relação ao modelado de acumulação Encostas Estruturadas em Avental de Colúvio estão situadas geralmente em zonas de meia encosta, onde suas bases são suavizadas com o preenchimento 
de grande quantidade de material coluvial provenientes do topo, que são transportados pelo escoamento superficial ou pela ação da gravidade através do processo de erosão diferencial. Nesse ponto percebeu-se a presença de dobramentos no relevo, que de acordo com Corrêa et al. (2010), foram gerados por esforços tectônicos ocorridos nessa área há milhões de anos (Figura 5a).

Observando desse ponto para o horizonte, no sentido oeste da superfície aplainada da Depressão Sertaneja, há diversas elevações residuais individualizadas ou em conjuntos de pouca extensão espacial, orientados na direção NE-SW. Essas feições são percebidas por conter formato arredondado, com aparência de cúpula e domo e encostas de inclinação moderada a escarpada. São plutons graníticos de rochas mais densas e resistentes aos processos denudacionais atuantes de pediplanação, constituindo os Inselbergs e Maciços Residuais, os quais possuem altitudes diferenciadas ao seu entorno, com cotas por volta de $400 \mathrm{~m}$ aos $700 \mathrm{~m}$ na área de estudo (Figura 5b). Nesse estudo, diferencia-se os Inselbergs dos Maciços, embora considerados Morros Testemunho, basicamente pelo formato e extensão. Os Maciços, ao contrário dos Inselbergs, possuem maior extensão e uma forma alongada, seguindo direções preferenciais determinadas por zonas de cisalhamento.

O desnível entre a área dos Domínios Morfoesculturais da Depressão Sertaneja e do Planalto da Borborema é resultante de estruturas brasilianas reativadas durante os esforços de ruptura continental do Cretáceo. Muitas dessas zonas de cisalhamento transcorrentes são antigas superfícies de empurrão, que podem desenvolver movimentos dextrais (sentido horário) ou sinistrais (sentido anti-horário) (ANGELIM, MEDEIROS, NESI, 2006; CORREA et al., 2010). Nas altas encostas dessas porções verifica-se uma vegetação com extrato arbustivo-arbóreo de caatinga bastante seca, enquanto nas baixas encostas há uma vegetação mais robusta, associada ao material coluvial que se encontra na base dessas encostas, induzindo a tipo de uso da terra diferente dos entornos (Figura 5c).

A área se encontra antropizada, onde ocorre o uso desordenado do solo por meio da mineração, das pastagens e das culturas de gêneros agrícolas de subsistência na planície fluvial do riacho Chafariz, que se encontra bastante assoreada e com a mata ciliar relativamente degradada. Nesse ponto, também se observa uma ampla utilização das rampas de Colúvio para desenvolvimento da agricultura (Figura 5d). 

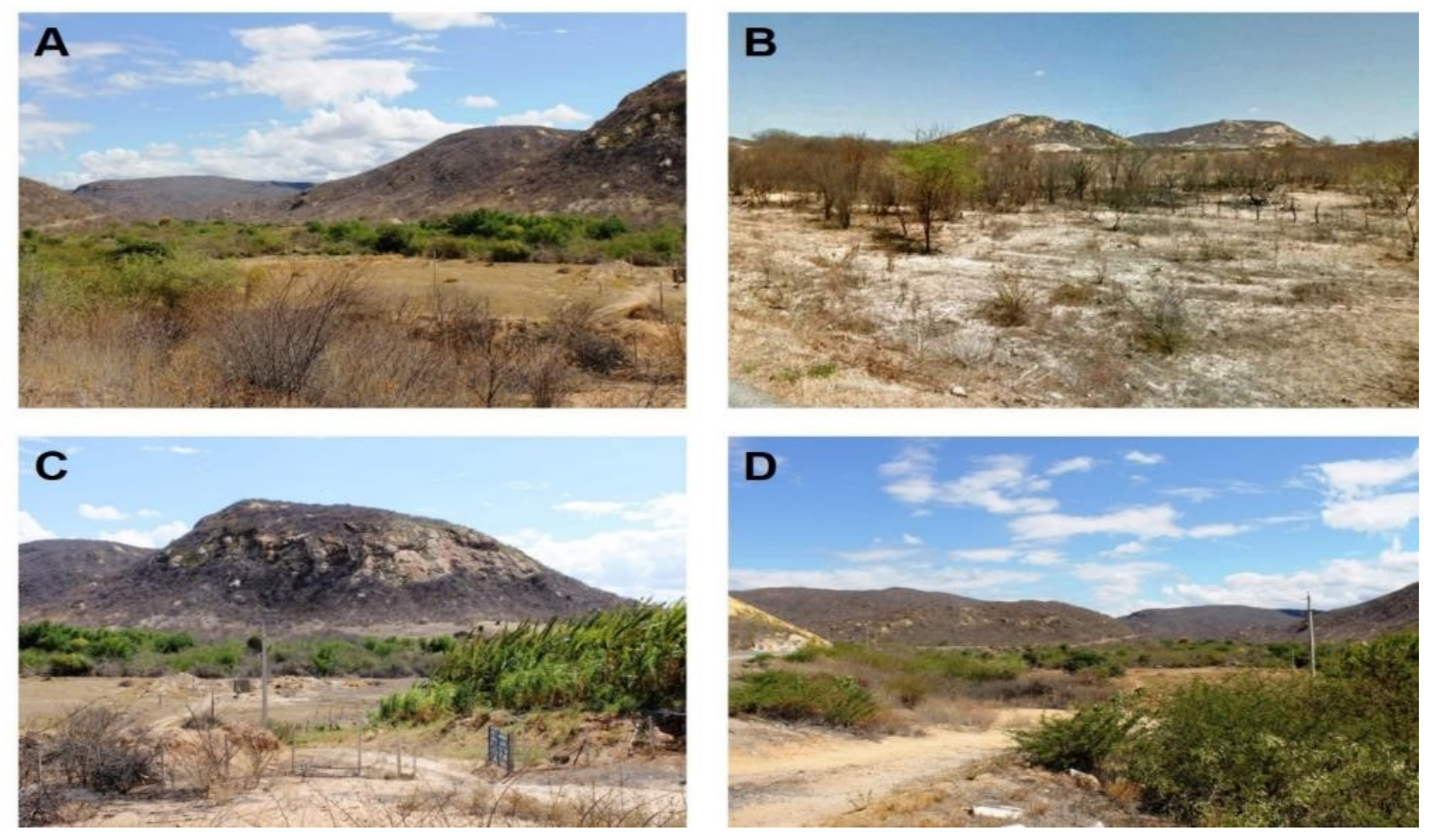

Figura 5 - A - Limite do front Ocidental da Borborema no contato com o Pediplano Sertanejo; B - Maciços residuais individualizados ou Inselbergs; C e D - área se encontra antropizada com uso para culturas agrícolas.

Fonte: Autores, 2018.

Ainda na Rodovia BR-230, no município do Junco do Seridó, analisou-se o terceiro ponto no Compartimento Seridó, onde há a presença de um material coluvionar de origem laterítica, remobilizado da alta encosta. O material é composto por fragmentos de laterita bastante alterada e oxidada, com a coloração marrom-avermelhada, blocos de quartzo e pequenos fragmentos de mica (Figura 6a).

Nesse ponto, foram identificadas encostas côncavas, com material bastante movimentado pela ação da erosão pluvial, o que ocasionou ravinamentos na encosta, resultante, também, da ação antrópica, onde se apresentam fortes sinais de supressão da vegetação (Figura 6b).

Alguns quilômetros após, na porção somital do Planalto da Borborema, foram observadas feições geomorfológicas tabulares que se prolongam no interior do referido planalto, formando chapadas e mesas com topos tabulares em altitudes que podem ultrapassar cotas dos 800 metros (Figura 6c). De acordo com Angelim, Medeiros, Nesi (2006) são feições residuais do relevo caracterizadas por bancadas sedimentares bastante elevadas e com topos planos que capeiam diversas serras interioranas, expostas como antigos horizontes exumados de litologia resistentes à erosão. Essas feições tabulares denominadas de cimeiras são acumulações sedimentares que afloram em relevo plano e levemente ondulado do Compartimento Seridó, com escarpas côncavas íngremes e topo plano, correspondendo a um antigo solo de horizonte B composto por arenitos de tamanho médio a conglomeráticos, argilosos e com crosta laterítica de rochas preexistentes, cumprindo a função de 
uma superfície ou nível de aplainamento, indicativos de um período mais úmido. São resquícios da Formação Serra dos Martins, onde sua formação ocorreu aproximadamente de 64 a 25 milhões de anos atrás (MORAIS NETO et al., 2008; DANTAS; FERREIRA, 2010). Essa área corresponde ao modelado Chapadas Sotopostas aos Maciços Cristalinos, que se localizam numa altitude entre 700m e $800 \mathrm{~m}$ ou acima (DINIZ et al., 2017).

Vale salientar que, por motivos de falta de nutrientes, a cobertura vegetal sobre essa crosta na alta encosta é mais baixa e de porte menor. Na baixa encosta a vegetação é mais robusta, onde é possível observar algumas ações de desmatamento em razão da ocorrência do mineral caulinita, demonstrando o forte intemperismo químico que atuou sobre este material. $\mathrm{Na}$ área, também se observa uma forte presença de extração mineral e também da agricultura (Figura 6d).

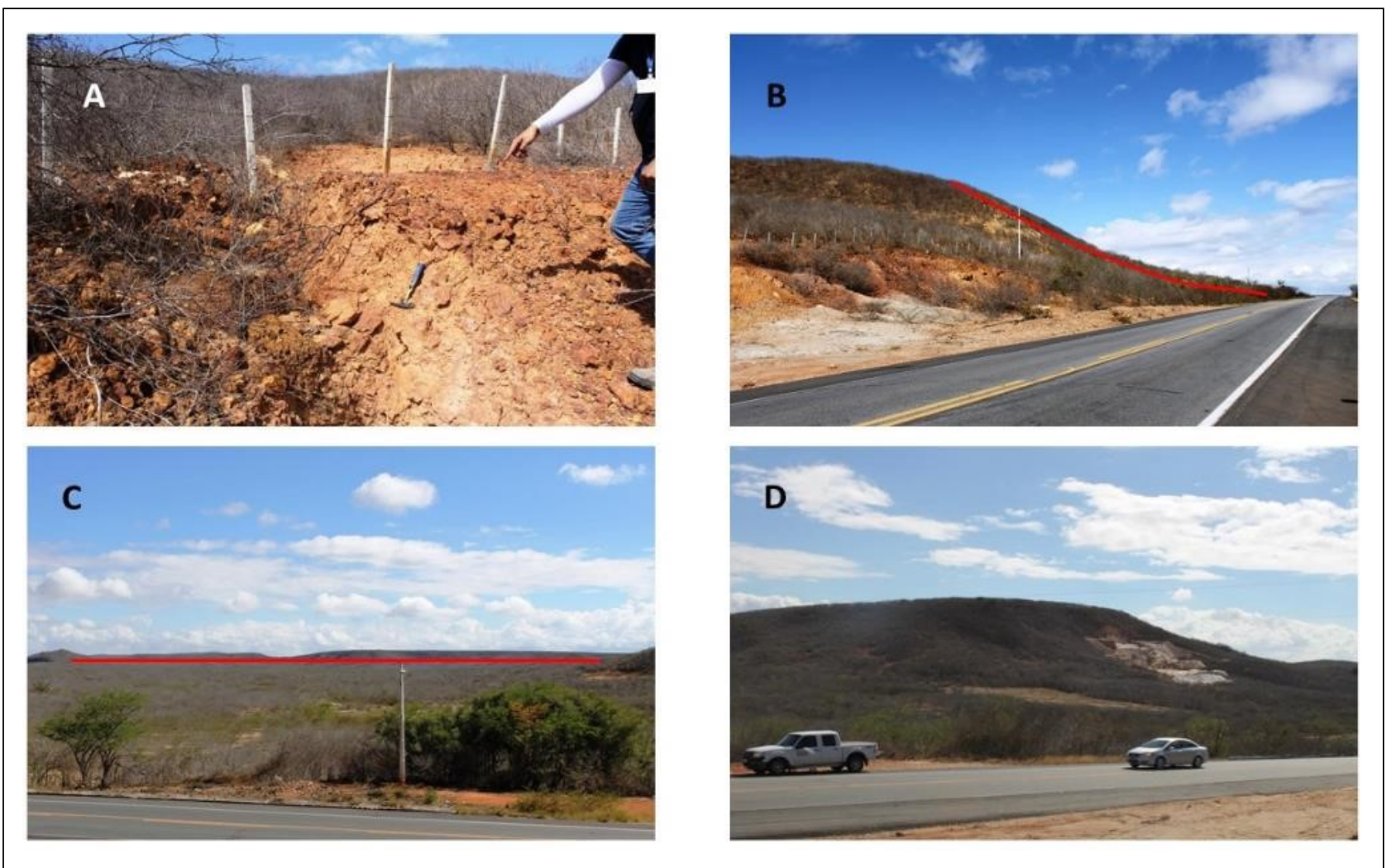

Figura 6 - A - Material coluvionar de origem laterítica bastante alterada e oxidada, com a coloração marromavermelhada, blocos de quartzo e pequenos fragmentos de mica fortemente remobilizado da alta encosta; B e C -

Feições do relevo com material de colúvio de origem laterítica em formas côncavas e tabulares; D - Ações de desmatamento em razão da ocorrência do mineral caulinita, com forte presença de atividades de extração mineral no entorno e também da agricultura.

Fonte: Autores, 2018.

Dando continuidade, na altura do povoado Pau dos Ferros, localizado no município de Equador/RN, foi detectado um Pedimento Embutido, que se encontra em altitudes variando nas cotas dos 450 aos 600 metros. Observou-se, portanto, uma área intermontana com declividades suaves, cercada por escarpas íngremes, composta por pavimentos detríticos e forte ocorrência de erosão linear, sulcos e ravinas. Essa área é um setor de transição entre as altas encostas e os pedimentos, a 
qual apresenta uma intensa dissecação do relevo com avançado estágio de desertificação. Nas áreas circundantes ocorrem elevações de topos tabuliformes a semiconvexos (Figura 7a).

Também se desenvolve nessa localidade, a atividade de caprinocultura e da agricultura de subsistência nos períodos chuvosos, além de uma intensa atividade antrópica associada à mineração nos demais meses do ano, além de extração e queima da vegetação natural para o forno das minerações. Devido às práticas inapropriadas da utilização dessa vegetação na área, a mesma vem sendo rapidamente transformada pela ação antrópica, apresentando elevado estágio de desertificação (Figura 7b).

Na porção leste da área, ocorrem encostas sem cobertura coluvial, que são áreas próximas à cimeira, em rampas com moderada inclinação, entre as cotas de 600 e 700 metros. São áreas propícias aos processos erosivos, ocasionando o surgimento de ravinas e voçorocas nas áreas instáveis da superfície, onde se formam o início das drenagens e divisores de água. Nessa área há uma abertura no relevo que pode se configurar uma garganta de superimposição de drenagem, que corta a serra das Queimadas, as quais são consequências de uma intensa ação tectônica e de fases alternantes de climas úmidos e secos, continuada pela reativação dos dobramentos que foram sucedidas pela formação de fraturas e falhas, além de contínuos aplainamentos e erosão (ANGELIM, MEDEIROS, NESI, 2006) (Figura 7c). No entanto, em função da escala trabalhada nesse estudo não ser de maior detalhe, não se torna visível e é impossível mapeá-la.

Essa é uma área bem diferenciada por causa dos recursos naturais disponíveis e que se encontram nas rochas pegmatíticas da região, onde se encontra uma diversidade de minerais metálicos, minerais industriais e gemas, as quais são as principais riquezas encontradas e extraídas tanto pelas empresas como pelos garimpeiros, tendo o caulim, feldspato, quartzo, micas, argilas, calcários, rochas ornamentais, pegmatitos e quartzitos como os principais da lista (Figura 7d). 

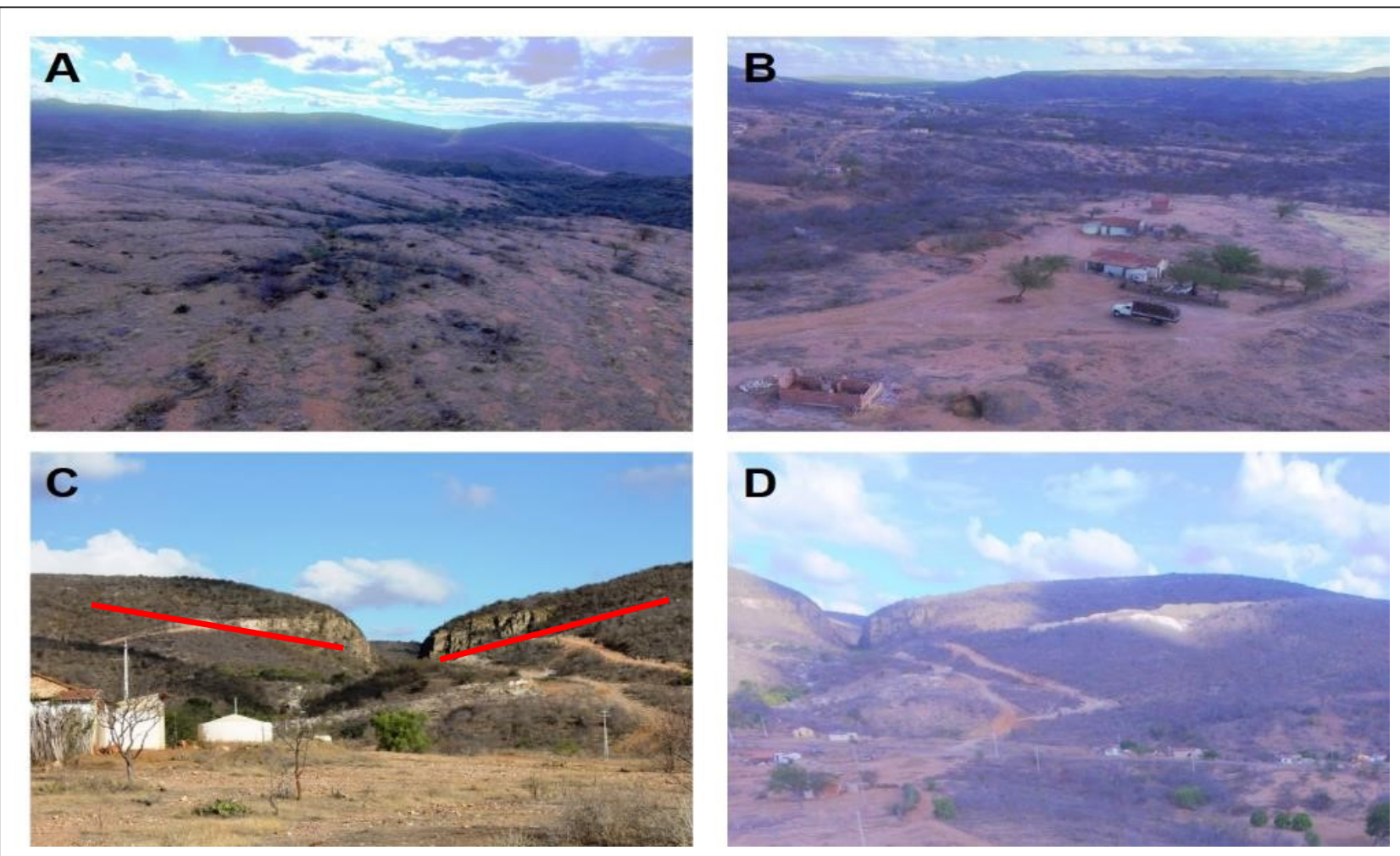

Figura 7 - A, B e D - Feições do relevo numa área pedimentar intermontana, com pavimentos detríticos e forte ocorrência de erosão linear, sulcos e ravinas apresentando avançado estágio de desertificação, devido o início de urbanização local em consequência da agricultura de subsistência e da intensa atividade de mineração; C - Abertura no relevo que pode se configurar uma garganta de superimposição de drenagem.

Fonte: Autores, 2018.

$\mathrm{Na}$ direção norte, na rodovia RN-086, ainda no município de Equador/RN, obtiveram-se novos dados em um local com cota altimétrica de 514 metros, correspondendo a um ponto dominado por Encostas com Cobertura Coluvial.

No local, ocorre um vale encaixado em sopé de alinhamento com cristas convexas, semiconvexas e semiplanas, apresentando sinais aparentes de intensa morfogênese, com formação de solos pouco profundos nas encostas através dos processos erosivos lineares que dissecam fortemente o relevo, gerando sulcos e ravinas em rampas de colúvio, havendo, também, aparentes processos de movimentação de massa. Tais feições coincidem, em razão de suas situações naturais, com uma maior fragilidade diante dos processos erosivos (Figura 8a).

A leste do ponto observou-se algumas feições com topos planos a levemente ondulados nas cotas de 800 metros ou superiores, com escarpas abruptas e contornos desiguais, com sinais de intensa dissecação, o que corresponde a unidade mais elevada da área, denominada Cimeira (Figura 8b).

A área em questão apresenta marcante controle estrutural e movimentação tectônica, exibindo vertentes com declividades e formas bem diversificadas, com claros sinais de recuo paralelo, relacionados aos principais processos de intemperismo, erosão e movimentos de massa. Como 
consequência da evolução de áreas falhadas, ocorrem feições típicas da evolução morfogenética de áreas dessa natureza, as Facetas Triangulares (Figuras 8c e 8d).
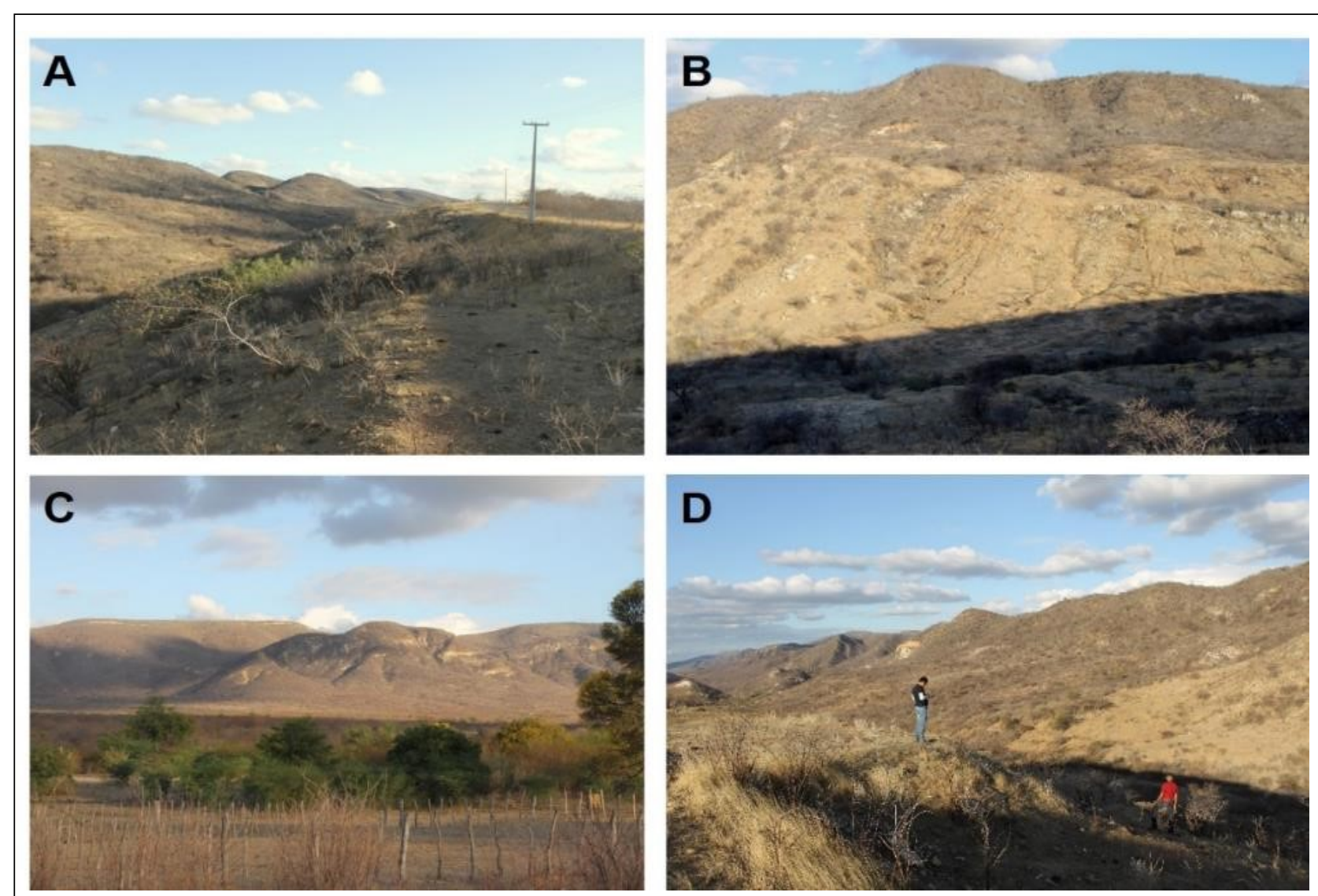

Figura 8 - A e B - Feições do relevo com vale encaixado em sopé de alinhamento em cristas convexas e côncavas, com marcante controle estrutural de direção NE-SW; C e D - vertentes com declividades e formas bem diversificadas, com claros sinais de recuo paralelo na Serra das Queimadas, município de Equador/RN.

Fonte: Autores, 2018.

\section{CONSIDERAÇÕES FINAIS}

O mapeamento geomorfológico é um produto essencial para a compreensão do desenvolvimento de uma paisagem. Nesse sentido, os estudos de planejamento territorial e ambiental, dentre outros, necessitam substancialmente, de produtos com qualidade advindos da cartografia geomorfológica.

A modelagem com os dados SRTM, apresentou notáveis resultados para o mapeamento geomorfológico da região. Desse modo, torna-se interessante replicar essa técnica em outras porções do Seridó e, porque não, do Semiárido do Nordeste Brasileiro.

Assim, a produção do mapeamento geomorfológico da folha Jardim do Seridó abre precedentes para outros estudos sobre o relevo da região com diferentes escalas e outros assuntos que envolva o tema. Esse mapeamento é de grande relevância, uma vez que se destina a representar e 
analisar o espaço geográfico em diferentes escalas espaciais, e possibilita a compreensão da gênese e evolução do relevo, consistindo em um importante documento para o planejamento territorial e gestão ambiental da área estudada.

O presente estudo foi pioneiro na região, pois não existe mapeamento geomorfológico de detalhe para essa área. Embora a região apresente uma baixa densidade populacional, já se constata um nível considerável de impacto ambiental, o que torna mais urgente redirecionar as ações de sustentabilidade.

\section{REFERÊNCIAS}

ANGELIM, L. A. A.; MEDEIROS, V. C.; NESI, J. R. Programa Geologia do Brasil - PGB. Projeto Mapa Geológico e de Recursos Minerais do Estado do Rio Grande do Norte. Mapa Geológico do Estado do Rio Grande do Norte. Escala 1:500.000. Recife: CPRM/FAPERN, 2006.

AZEVEDO, F. F. Desenvolvimento Regional e Potencial Turístico no Seridó Potiguar. Natal/RN: EDUFRN, 2014. 194p.

BRITO NEVES, B. B. América do Sul: quatro fusões, quatro fissões e o processo acrescionário andino. SIMPÓSIO NACIONAL DE ESTUDOS TECTÔNICOS, 7, Bahia, SBG. 11-13, 1999.

CASSETI, V. Geomorfologia. Livro Digital [S.1.]: [2005]. Disponível em:

$<$ https://geografiaambiental.files.wordpress.com/2010/12/geomorfologia.pdf $>$. Acesso em:

$15 / 06 / 2019$.

CHRISTOFOLETTI, A. Geomorfologia. 2a ed. São Paulo/SP: Editora Edgard Blucher LTDA, 1980. $188 \mathrm{p}$.

CPRM, SERVIÇO GEOLÓGICO DO BRASIL. Glossário Geológico Ilustrado - 2017. Disponível em: < http://sigep.cprm.gov.br/glossario/>. Acesso em: 05/05/2019.

COELHO NETTO, A. L. Hidrologia de encosta em interface com a geomorfologia. In: GUERRA, A. J. T; CUNHA, S. B. (Org.). Geomorfologia: uma atualização de bases e conceitos. $7^{\text {a }}$ ed. Rio de Janeiro: Bertrand Brasil, 2007. Cap. 3, p 93-209.

CORRÊA, A. C. B.; TAVARES; B. A. C.; MONTEIRO, K. A.; CAVAlCANTI, L. C. S.; LIRA; D. R. Megageomorfologia e morfoestrutura do Planalto da Borborema. Revista do Instituto Geológico, São Paulo, v. 31, n. 1-2, p. 35-52, 2010.

DANTAS, M. E.; FERREIRA, R. V. Relevo. In: PFALTZGRAFF, P. A. S.; TORRES, F. S. M. (Org.). Geodiversidade do estado do Rio Grande do Norte. Recife: CPRM. p. 77-92. 2010.

DINIZ, M. T. M.; OLIVEIRA, G. P.; MAIA, R. P.; FERREIRA, B. Mapeamento geomorfológico do estado do Rio Grande do Norte. Revista Brasileira de Geomorfologia, São Paulo, v. 18, n. 4, p. 689$701,2017$.

EMBRAPA - Empresa brasileira de pesquisa agropecuária. Centro Nacional de Pesquisa de Solos (Rio de Janeiro, RJ). Sistema brasileiro de classificação de solos. $2^{\mathrm{a}}$ ed. Rio de Janeiro: EmbrapaSPI, 2009. 412 p. 
FERREIRA, B. A região semiárida nordestina: utilização dos dados SRTM para mapeamento geomorfológico de parte dos municípios de Jatobá Petrolândia e Tacaratu, Sub-Médio São Francisco, PE. Revista Ciência e Natura, UFSM, n. 32, p. 143-158, 2010.

HÉTU, B. Uma Geomorfologia socialmente útil: os riscos naturais em evidência. Mercator - Revista de Geografia da UFC, ano 02, número 03, 2003.

IBGE - Fundação Instituto Brasileiro de Geografia e Estatística. Manual Técnico de Geomorfologia. (Série Manuais Técnicos em Geociências n. 5), Rio de Janeiro, 1995. 175p.

. Manual Técnico da Vegetação Brasileira. (Série Manuais Técnicos em Geociências n. 1), Rio de Janeiro, 2012. 271p.

GUERRA, A. T.; GUERRA, A. J. T. Novo dicionário geológico-geomorfológico. Rio de Janeiro: Bertrand Brasil, 1997. 652 p.

MAIA, R. P.; BEZERRA, F. H. R. Tópicos de Geomorfologia Estrutural: Nordeste Brasileiro. Fortaleza: Ed. UFC, 2014. 124p.

MAIA, R. P.; AMARAL, R. F.; GURGEL, S. P. P. Geomorfologia do Rio Grande do Norte. In: ALBANO, G. P.; FERREIRA, L; ALVES, A. M. (Org.). Capítulos de Geografia do Rio Grande do Norte. Natal: Fundação José Augusto, 2013. Cap. 1, p. 20-59.

MINISTÉRIO DO MEIO AMBIENTE - MMA; Secretaria de Recursos Hídricos. Panorama da desertificação no Estado do Rio Grande do Norte. Natal-RN, 2005.

MORAIS, I. R. D. Seridó norte-rio-grandense: uma geografia da resistência. Caicó: edição do Autor, 2005. 422p.

MORAIS NETO, J. M; GREEN, P. F.; GARNER, G. D.; ALCKMIM, F. F.; Age of the Serra do Martins Formation, Borborema Plateau, northeastern Brazil: constraints from apatite and zircon fission track analysis. Boletim de Geociências da Petrobrás, Rio de Janeiro, v. 16, n. 1, p. 23-52, 2008.

OLIVEIRA, G. P.; DINIZ, M. T. M.; FERREIRA, B.; BERNARDINO, D. S. M. Mapeamento morfoestrutural e morfoescultural do Seridó Potiguar. In: XI SINAGEO - Simpósio Nacional de Geomorfologia, 2016. Maringá/PR. Anais do XI SINAGEO, 2016.

PTDRS - Plano Territorial de Desenvolvimento Rural Sustentável do Seridó. 2010. Disponível em: http://sit.mda.gov.br/download.php>. Acesso em: 21/05/2019.

RIO GRANDE DO NORTE; SEPLAN; IICA. Plano de desenvolvimento sustentável do Seridó: v. 1 - Diagnóstico; v. 2 - Estratégias, programas e projetos e sistema de gestão. Caicó, set. 2000.

ROSS, J. L. S. O registro cartográfico dos fatos geomorfológicos e a questão da taxonomia do relevo. Revista do Depto. Geografia, FFLCH-USP, São Paulo, v. 6, n. 1, p. 17-29, 1992.

ROSS, J. L. S. Análise Empírica da Fragilidade dos Ambientes Naturais Antropizados. Revista do Depto. Geografia, FFLCH-USP, São Paulo, n. 8, p. 63-74, 1994. 
VITAL, S. R. O. Sensibilidade paisagística e grau de instabilidade: um estudo da dinâmica geomorfológica em área com risco de erosão no alto curso da sub-bacia do rio Taperoá, estado da Paraíba, Nordeste do Brasil. 2011. 110 f. Dissertação (Mestrado em Geografia) - Centro de Filosofia e Ciências Humanas da Universidade Federal de Pernambuco, Recife, 2011.

Trabalho enviado em 05/09/2019

Trabalho aceito em 01/10/2019 